\title{
Persistence Behaviour of Pre-Mix Formulation of Profenophos and Cypermethrinin/on Sapota Fruit
}

\author{
Vanrajsinh H. Solanki*, Susheel Singh, Kelvin D. Gandhi, \\ Kamlesh G. Patel and Keyur N. Patel
}
Food Quality Testing Laboratory, N.M. College of Agriculture, Navsari Agricultural University, Navsari (Gujarat)-396 450, India

*Corresponding author

\section{A B S T R A C T}

\section{Keywords}

Chlorpyrifos, Cypermethrin, Distribution, Dissipation, GCECD, QuEChERS, Sapota, Waiting period

Article Info

Accepted:

10 December 2018

Available Online:

10 January 2019
Persistence behavior of individual insecticides of pre-mix formulation (chlorpyrifos and cypermethrin) was studied in peel, pulp and whole sapota fruit (unripe and ripe) applied at recommended and double of recommended dose. The residues of cypermethrin and chlorpyrifos persisted up to 10-30 days at either dose in peel, pulp and whole unripe sapota fruits. The dissipation half-life (DT-50) values obtained for chlorpyrifos and cypermethrin in peel and whole fruit was in the range of 2.57 to 5.01 days at recommended and double the recommended dose. Residues of both insecticides were detected in unripe and ripe sapota peel but were absent in unripen sapota pulp at either doses. Chlorpyrifos residues were detected in ripe sapota pulp at both doses but cypermethrin residues were absent at recommended dose in ripe sapota pulp. The cypermethrin and chlorpyrifos residues were not detected in soil samples on $30^{\text {th }}$ days at either dose but were detected in initial soil samples in both the doses.

\section{Introduction}

Sapota (Manilkara achras Mill.) commonly known as sapodilla or chiku, belongs to family Sapotaceae and widely spread over tropical agro-climatic condition in Southern Mexico, Central America, Sri Lanka, India, Jamaica and Philippines. India is considered to be the largest producer of sapota in the world with an area of about 163.9 thousand ha with a production of 1495.0 metric tonnes (Annonymous, 2014). Although, sapota is widely grown in several western and southern states of India but it is major fruit crops of Gujarat. It is mainly exported to gulf nations, USA, Canada, UK, Singapore and other countries. Traditionally, sapota was considered to be a hardy species that needs little attention of farmers for controlling the pests and diseases. This notion was changed in recent past due to rapid expansion and monoculture of this crop along with an increase in pest complex of sapota in recent past in India (Somdutt, 2001). Sapota is 
attacked by more than 25 insect pests which include bud borer, sapota moth, midrib folder, leaf miner, fruit flies and sucking pests (Butani, 1979 and Jhala et al., 1986). Among these, sapota bud borer (Anarsia achrasella) is a major and regular pest causing damage to the sapota crop. The larva could damage up to 36.9 - $46.6 \%$ buds before reaching pupation (Jayanthi et al., 2006). Application of pre-mix formulation of chlorpyrifos + cypermethrin at the rate of $0.055 \%$ in/on sapota tree provided significant control of sapota bud borer (Anarsia achrasella) over other insecticides (Suryavanshi and Patel, 2009). Further, the use of pre-mix formulations containing mixture of insecticides with different chemistry is picked up the pace among farmers over single insecticides due to assurance of prolonged, wide spectrum and effective control of various insect pests also check the problem of resistance in pest. These formulations are found effective in controlling the insect pest of fruits and vegetables. Though, above pre-mix formulation of chlorpyrifos + cypermethrin is widely adopted by sapota of South Gujarat. The best survey of literature reveals that present investigation might be the first scientific attempt to report the persistence and distribution pattern of premix formulation in/on sapota fruit. Therefore, present study was carried out to determine the dissipation behavior and distribution pattern of individual residues of pre-mix formulation (chlorpyrifos+cypermethrin) in/on peel, pulp and whole ripe and unripe sapota fruit and soil.

\section{Materials and Methods}

\section{Chemicals and reagents}

The neat certified reference material of chlorpyrifos (99.6\% purity) and cypermethrin (99.8\% purity), was procured from SigmaAldrich India Ltd., Bangalore. Chemical structures of the active ingredients present in these formulations are given in table 5. The stock solution was prepared with HPLC grade organic solvents ( $n$-hexane:acetone, v/v 9:1) and further diluted to prepare the intermediate and working standards. All other chemicals, reagents and solvents used were of HPLC grade. The pre-mix formulation of chlorpyrifos + cypermethrin $\left(\mathrm{NAAG}^{\circledR}\right.$ 55EC) manufactured by M/S Safex Chemicals India Pvt. Ltd. was purchased from local market.

\section{Field experiment}

A field experiment was performed at Agriculture Experimental Farm, Navsari Agricultural University, Navsari, Gujarat, India. The pre-mix formulation of chlorpyrifos + cypermethrin was applied on sapota variety, kalipatti following good agricultural practices. The experiment was conducted in randomized block design with three replications. The treatments applied were control (spray of water), recommended dosei.e. $1.0 \mathrm{~mL} \mathrm{~L} \mathrm{~L}^{-1}$ $\left(3300 \mathrm{~g}\right.$ a.i.ha ${ }^{-1}$; chlorpyrifos $3000+$ cypermethrin $300 \mathrm{~g}$ a.i.ha ${ }^{-1}$ ) and double to the recommended dose $2.0 \mathrm{mLL}^{-1}$ i.e. $6600 \mathrm{~g}$ a.i.ha ${ }^{-1}$ (chlorpyrifos $6000+$ cypermethrin600g a.i.ha ${ }^{-1}$ ). Total 11 rows consists of 10 sapota trees spaced apart $(5 \mathrm{mx} 5 \mathrm{~m})$ were selected and 3 rows were allotted for each treatment and 1 buffer row was left in between two treatments to check the effect of spray drift. The spray volume taken was 15 litres per tree. The foliar spray of the insecticidal treatments applied once with the help of Maruti Foot Sprayer on the second fortnight of February when major flush of fruits were harvested. The sapota fruits were collected on 0 ( $2 \mathrm{~h}), 1,3,5$, $7,10,20,30$ days after the application. To determine the persistence of chlorpyrifos + cypermethrin residue in/on sapota fruit 3 to 4 fruits (approximately $200 \mathrm{~g}$ ) were harvested from each tree and composited to get $2 \mathrm{~kg}$ samples from each replication and carried to the laboratory for processing. The $50 \%$ of sapota fruit samples collected on zero days ( 2 hrs after spray) were cleaned by rubbing with the hand and rolling on gunny bags followed 
by thorough rinsing with tap water for 3-5 min and shade dried. After that sapota fruits were dried with muslin cloth and kept under ambient temperature till $80 \%$ of the fruits were ripened. The ripened samples (after 7 days) were analysed for probable presence of residues of chlorpyrifos and cypermethrin.

\section{Distribution study}

Prior to analysis, the unripe medium sapota fruits (24 units) were collected, rinsed, dried and their weight was recorded. Later, these fruits were peeled off and the peel and pulp were kept separately weighed. The average weight of sapota fruit, peel and pulp was recorded 74.7, 5.8 and $68.9 \mathrm{~g}$, respectively. Later, peel and pulp of the sapota fruits were analysed separately to determine the distribution pattern and dissipation behaviour of chlorpyrifos + cypermethrin.

Dissipation behaviour of these insecticides in whole fruit was also determined by extrapolating the residue data (Bostanian et al., 1993). The soil samples were collected on 0 and 30 days after the last application. Approximately $2 \mathrm{~kg}$ soil samples were collected from 10 sampling sites per treatment with standard sampling procedure. Prior to analysis, soil samples were mixed thoroughly, air dried milled and passed through $2 \mathrm{~mm}$ sieve and then subjected to pesticide residues analysis. Extraction and clean-up of chlorpyrifos and cypermethrin residues in sapota fruits and soil were carried out according to QuEChERS method (AOAC Official Method, 2007) with certain modifications.

\section{Extraction procedure}

\section{Sapota peel and pulp}

Homogenised sapota peel and pulp samples $(15 \pm 0.1 \mathrm{~g})$ were extracted in $50 \mathrm{~mL}$ capacity polypropylene centrifuge tube with $15 \mathrm{~mL}$ acetonitrile $1 \%$ of acetic acid. Subsequently, $6.0 \mathrm{~g}$ of magnesium sulphate (anhydrous) and $1.5 \mathrm{~g}$ sodium acetate (anhydrous) were added and mixed properly using vortex mixture for 1 minute. After mixing tubes were centrifuged at $3500 \mathrm{rpm}$ (2205 rcf) for 2 minutes. For clean up $6.0 \mathrm{~mL}$ (equivalent to $6 \mathrm{~g}$ sample) supernatant transferred to $15 \mathrm{~mL}$ capacity polypropylene centrifuge tube containing 300 $\mathrm{mg}$ of PSA and $900 \mathrm{mg}$ of $\mathrm{MgSO}_{4}$. The tubes were mixed well and centrifuged at $2500 \mathrm{rpm}$ (1125 rcf) for 2 minutes. Following this, an aliquot of $2 \mathrm{~mL}$ was drawn and subsequently evaporated to dryness at $45^{\circ} \mathrm{C}$ under gentle stream of nitrogen with calipar life science make TurboVap ${ }^{\circledR}$. Finally, the volume of the samples was reconstituted to $2.0 \mathrm{~mL}$ with $n$ hexane: acetone (v/v, 9:1) for gas chromatographic analysis.

\section{Soil}

Representative soil sample $(10 \pm 0.1 \mathrm{~g})$ was extracted with $20 \mathrm{~mL}$ acetonitrile in $50 \mathrm{~mL}$ capacity polypropylene centrifuge tube. The adsorbents $\mathrm{MgSO}_{4}(4.0 \mathrm{~g})$ and $\mathrm{NaCl}(1.0 \mathrm{~g})$ was added and followed by vigorous shaking on vortex mixture for 1.0 minutes and centrifugation at $3500 \mathrm{rpm}$ ( 2205 rcf) for 2.0 minutes. Then, an aliquot of $10 \mathrm{~mL}$ was transferred to a $15 \mathrm{~mL}$ centrifuge tube containing $\mathrm{MgSO}_{4}(1.5 \mathrm{~g})$ and PSA (0.25 g) followed by centrifugation at $2500 \mathrm{rpm}$ (1125 rcf) for 2.0 minutes. Subsequently, an aliquot of $4 \mathrm{~mL}$ was transferred to the test tube and evaporated to dryness. Finally, the volume was made up to $2.0 \mathrm{~mL}$ using $n$-hexane: acetone $(9: 1, \mathrm{v} / \mathrm{v})$ and quantitative analysis was performed on GC-ECD.

\section{Instrumental parameters}

A gas chromatograph (TRACE GC ULTRA ${ }^{\circledR}$ ) equipped with electron capture detector (ECD) and TRIPLUS auto-sampler was used for quantitative analysis of chlorpyrifos and cypermethrin from sapota (peel and pulp) and 
soil sample. The chromatographic separation was performed on capillary column (AB-5, 30 $\mathrm{m} \times 0.25 \mathrm{~mm}$ i.e., $0.25 \mu \mathrm{m}$ FT). The $1.0 \mu \mathrm{L}$ sample was injected under splitless mode into GC. Ultra-pure helium (99.999\%) gas was used as carrier gas at a flow rate of 1.0 $\mathrm{mLmin}^{-1}$. The oven temperature was initially maintained at $220^{\circ} \mathrm{C}$ for 4 minutes and programmed with the ramp of $15^{\circ} \mathrm{Cmin}^{-1}$ to attain the final temperature of $290^{\circ} \mathrm{Cwhich}$ was maintained for 4 minutes. Injector and detector temperatures were maintained at 230 and $300^{\circ} \mathrm{C}$, respectively. The reference current of ECD was $1.0 \mathrm{nA}$. Under these parameters, the retention time of chlorpyrifos and cypermethrin was 4.69 and 9.96 minutes, respectively (Fig. 1).

Total residues in whole fruit $(\mu \mathrm{g} / \mathrm{g})$

$=\frac{(\text { Residue in peel }(\mu \mathrm{g} / \mathrm{g}) X \text { peel wt }(\mathrm{g})+\text { Residue in pulp }(\mu \mathrm{g} / \mathrm{g}) X \text { pulp wt }(\mathrm{g}))}{\text { total weight of fruit }(\mathrm{g})}$

\section{Results and Discussion}

\section{Behaviour of chlorpyrifos}

\section{Method verification}

A linearity study was performed on GLC-ECD to obtain the linear dynamic range of the chlorpyrifos by plotting graph of detector's response $v / s$ concentration. The regression equation and co-efficient of determination $\left(\mathrm{R}^{2}\right)$ worked out for chlorpyrifos is $\mathrm{y}=83619 \mathrm{x}$ $+1905.2 ; \mathrm{R}^{2}=0.996$ (chlorpyrifos).

The per cent recovery of chlorpyrifos was recorded in the range of 87.25-110.41, 84.7496.24 and 81.45-97.54 for sapota pulp, sapota peel and soil at different spiking levels, respectively. The limit of quantification (LOQ) of the analytical methods for chlorpyrifos was $0.004 \mathrm{mg} \mathrm{kg}^{-1}$ for sapota fruit and $0.011 \mathrm{mg} \mathrm{kg}^{-1}$ for soil (Table 1).

\section{Method verification study}

To establish the reliability and efficiency of pesticide residue analysis method, method verification study for sapota peel, sapota pulp and soil was performed with the following parameters: accuracy (\% recovery), precision (\% relative standard deviation), linearity, limit of detection (LOD) and limit of quantification (LOQ). The accuracy and precision of the analytical method was verified on three spiking levels $0.025,0.10$ and $0.50 \mu \mathrm{g}^{-\mathrm{g}^{-1}}$ level from peel, pulp and soil. The residue data was subjected to statistical analysis according to Hoskins (1961) to compute the residual halflife (DT-50) and safe pre-harvest interval (PHI) i.e. waiting period. The residues for whole sapota fruits were calculated by using following formula (Bostanian, 1993).

\section{Dissipation study}

The degradation kinetics of chlorpyrifos was studied by fitting the data into first-order rate equation as the co-efficient of variation $\left(\mathrm{R}^{2}\right)$ was $\geq 0.95$ which reflect a strong relation between independent factor (residues) and time (days after application). Initial residues of chlorpyrifos recorded in recommended dose and double to the recommended dose in sapota peel on 0 day were 1.83 and $2.65 \mathrm{mg} \mathrm{kg}^{-1}$, respectively. The chlorpyrifos residues declined gradually and reduced to $99.56 \%$ on $20^{\text {th }}$ day in recommended dose and $99.62 \%$ on $30^{\text {th }}$ day in double to the recommended dose with respect to their initial residues. No residues of chlorpyrifos were detected in sapota pulp at either dose on any sampling day. The extrapolated residues of chlorpyrifos in whole sapota fruit (peel+ pulp) obtained on zero day were 0.142 and $0.206 \mathrm{mg} \mathrm{kg}^{-1}$ at recommended and double to recommended dose, respectively and were below to the 
detection level on $20^{\text {th }}$ and $30^{\text {th }}$ day after last application at recommended and double to recommended dose, respectively (Table 2). The half-life (DT-50) value recorded for chlorpyrifos in sapota peel for recommended and double to recommended dose were 2.57 and 4.0 days, respectively. The safe waiting period obtained for chlorpyrifos residues in sapota peel was 13.6 days for recommended dose and 23.29 days for double to the recommended dose. The half-life value worked out for chlorpyrifos in whole sapota fruit were 2.57 and 4.60 days and waiting period was 4.18 and 9.08 days for recommended and double to recommended doses, respectively (Table 3).

\section{Distribution study}

Chlorpyrifos residues detected in peel obtained from ripened sapota fruits were 0.01 and $0.03 \mathrm{mgkg}^{-1}$ for recommended and double to the recommended dose, respectively. Whereas, for pulp, chlorpyrifos residues were 0.008 and $0.023 \mathrm{mg} \mathrm{kg}^{-1}$ for recommended and double to the recommended dose, respectively. The chlorpyrifos residues detected in whole ripen sapota fruit were 0.008 and $0.024 \mathrm{mgkg}^{-1}$ at recommended and double to recommended doses which indicates 94.36 and $88.34 \%$ loss over initial residues recorded in whole unripe sapota fruit at respective doses (Table 4 ). The chlorpyrifos residues recovered in soil samples after application collected on 0 days was 0.34 and $0.53 \mathrm{mg} \mathrm{kg}^{-1}$ for recommended and double to the recommended dose, respectively. Chlorpyrifos residues were beyond detection level in soil samples collected on 30 day.

\section{Behaviour of cypermethrin}

\section{Method verification}

Similarly, linearity study was performed on GLC-ECDto obtain the linear dynamic range for cypermethrin by plotting graph of detector's response $v / s$ concentration. The regression equation for cypermethrin is $\mathrm{y}=$ $58519 x-2395$ and $R^{2}=0.999$. The linear dynamic range recorded for both insecticides lies between 0.01 and $1.0 \mathrm{mgkg}^{-1}$ with acceptable $\mathrm{R}^{2}$ values i.e. $>0.99$. In case of cypermethrin percent recovery obtained in sapota peel, pulp and soil was 88.74-104.22, 92.73-103.47 and 91.12-99.47respectively. The LOQ of the analytical methods for cypermethrin was 0.006 and $0.010 \mathrm{mg} \mathrm{kg}^{-1}$ for sapota fruit and soil, respectively. The method verification study reveals that the analytical method employed for residue analysis of both insecticides from sapota peel, pulp and soil was accurate (recovery; 81.45-110.41\%), precise (\% RSD; 3.94-10.98) and sensitive enough (LOQ <MRL i.e. $0.05 \mathrm{mg} \mathrm{kg}^{-1}$ as per SANCO guidelines (2013) (Table 1).

\section{Dissipation study}

Although, the residues of cypermethrin dissipated more rapidly than chlorpyrifos in peel and whole fruit at recommended and double to recommended doses. Initial residues of cypermethrin recorded in recommended dose and double to the recommended dose in sapota peel on 0 day were 0.26 and $0.32 \mathrm{mg}$ $\mathrm{kg}^{-1}$, respectively. The cypermethrin residues declined rapidly and reduced to $88.46 \%$ and $87.50 \%$ on $10^{\text {th }}$ day in recommended dose and double to the recommended dose, respectively. Thus, the residue of cypermethrin is persisting up to 10 day after last application. No residues of cypermethrin were detected in sapota pulp at either dose on any sampling day. The extrapolated residues of cypermethrinin whole sapota fruit (peel+ pulp) obtained on zero day were 0.020 and $0.025 \mathrm{mg} \mathrm{kg}^{-1}$ at recommended and double to recommended dose, respectively and were below to the detection level on $10^{\text {th }}$ day after last application at recommended and double to recommended dose, respectively (Table 2). The half-life (DT-50) value observed for cypermethrin in sapota peel for recommended 
and double to recommended dose were 3.41 and 3.49 days, respectively. The safe waiting period obtained for cypremethrin residues in sapota peel was 8.38 days for recommended dose and 19.21 days for double to the recommended dose. The half-life value worked out for cypermethrin in whole sapota fruit were 3.83 and 5.01 days. The waiting period for whole unripe sapota fruit worked out for cypermethrin was 1 day (Table 3 ) as the cypermethrin residues obtained on 0 day from both doses were less than the MRL of cypermethrin fixed by the European Union i.e. $0.05 \mathrm{mg} \mathrm{kg}^{-1}$.

\section{Distribution study}

Similar trend like chlorpyrifios was observed in distribution of cypermethrin residues in sapota peel and pulp. The cypermethrin residues detected in peel obtained from ripened sapota fruits were $0.005 \mathrm{mg} \mathrm{kg}^{-1}$ for recommended dose and $0.006 \mathrm{mgkg}^{-1}$ for double to recommended dose. But, for pulp, cypermethrin residues were BDL and 0.008 $\mathrm{mgkg}^{1}$ for recommended and double to the recommended dose, respectively. While, in sapota pulp cypermethrin residues were not detected at any of the stages in both the treatment. The cypermethrin residues detected in whole ripen sapota fruit were 0.004 and $0.008 \mathrm{mgkg}^{-1}$ at recommended and double to recommended doses which indicates 98 and $68 \%$ loss over initial residues recorded in whole unripe sapota fruit at respective doses (Table 4). Cypermethrin residues in soil were found below detection level on 0 day as well as on 30 day for both the doses.

Chlorpyrifos residues were detected in the peel of unripe sapota fruit but these were absent in pulp. In case of unripe sapota, residues of either insecticide were not transferred from peel to pulp. Whereas residues of chlorpyrifos were detected in peel, pulp and whole ripened sapota fruits which indicates a distinguishable transfer of chlorpyrifos residues from peel to pulp due to ripening process. However cypermethrin residues were observed in peel, pulp and whole ripen sapota fruit at double dose but these were absent in ripen sapota pulp at recommended dose but this phenomenon was not observed for cypermethrin residues.

From the results of unripe sapota fruits, it is evident that insecticide residues were not transferred from sapota peel to pulp at either dose. This restricted movement of residues might be facilitated by the chemical nature of insecticide and composition of sapota fruits. The main factors that might affect the penetration of a pesticide residue are the characteristics of the pesticide $\left(\mathrm{K}_{\mathrm{ow}}\right.$, molar mass, systemic action and the formulation of applied pesticide) in relation to the nature of the commodity (Table 5).

The initial concentration of the pesticide residues and the processing temperature could also affect penetration mechanism significantly (Amvrazi, 2011). However, pesticide with average distribution ratios more than $90 \%$ in peels were those with the lower water solubility $\left(<2.0 \mathrm{mgL}^{-1}\right) \quad(\mathrm{Xu}$ et al., 2012). Chlorpyrifos and cypermethrin are nonsystematic insecticides and having limited to very limited water solubility (1.4 and 0.004 $\mathrm{mgL}^{-1}$ ) and higher octanol water coefficient $\left(\mathrm{K}_{\mathrm{ow}}\right.$ i.e. 4.96 and 6.6$)$ which indicates a substantial affinity of both the insecticide towards organic solvents than water (Table5). This might be probable reason for the no trans-peel migration of both insecticides in sapota fruit. Further, the unripe sapota fruits composed of latex, tannin, aldehyde, and sapotin, gummy latex containing $15 \%$ rubber and $38 \%$ resin. The gummy latex is composed of D-xylose, L-arabinose, D-glucuronic acid and 4-Omethyl-D-glucuronic acid in a molar ratio of 2.2:1:0.42:0.58 (Lambert, 1968). 
Table.1 Recovery study of chlorpyrifos and cypermethrin residues in sapota pulp, sapota peel and soil

\begin{tabular}{|c|c|c|c|c|c|c|}
\hline \multirow{3}{*}{$\begin{array}{l}\text { Level of spiking } \\
\quad\left(\mathrm{mg} \mathrm{kg}^{-1}\right)\end{array}$} & \multicolumn{6}{|c|}{ *Average residues recovered $(\%) \pm$ SD } \\
\hline & \multicolumn{3}{|c|}{ Chlorpyrifos } & \multicolumn{3}{|c|}{ Cypermethrin } \\
\hline & SapotaPulp & SapotaPeel & Soil & SapotaPulp & SapotaPeel & Soil \\
\hline 0.025 & $87.25 \pm 5.20$ & $84.74 \pm 4.56$ & $83.12 \pm 15.14$ & $104.22 \pm 9.24$ & $92.73 \pm 10.87$ & $98.21 \pm 13.24$ \\
\hline 0.1 & $99.54 \pm 4.86$ & $91.16 \pm 3.33$ & $97.54 \pm 9.41$ & $98.41 \pm 7.65$ & $103.47 \pm 8.52$ & $99.47 \pm 10.67$ \\
\hline 0.5 & $110.41 \pm 5.12$ & $96.24 \pm 2.87$ & $81.45 \pm 4.25$ & $88.74 \pm 3.98$ & $96.24 \pm 4.21$ & $91.12 \pm 3.24$ \\
\hline **Mean Recovery & $99.06 \pm 5.06$ & $90.71 \pm 3.58$ & $87.37 \pm 9.60$ & $97.12 \pm 6.96$ & $97.48 \pm 7.86$ & $96.26 \pm 9.05$ \\
\hline \% RSD & 5.10 & 3.94 & 10.98 & 7.16 & 8.07 & 9.40 \\
\hline $\operatorname{LOD}\left(\mathrm{mg} \mathrm{kg}^{-1}\right)$ & 0.001 & 0.001 & 0.001 & 0.002 & 0.002 & 0.002 \\
\hline LOQ $\left(\mathrm{mg} \mathrm{kg}^{-1}\right)$ & 0.004 & 0.004 & 0.011 & 0.006 & 0.006 & 0.010 \\
\hline
\end{tabular}

*Average of seven replicate analyses, MRL for chlorpyrifos- $0.05 \mathrm{mg} \mathrm{kg}^{-1}$, MRL for ccypermthrin-0.05mg kg ${ }^{-1}$ (EU pesticide database,2016)

** Average recovery across the fortification levels

Table.2 Residues and per cent dissipation of chlorpyrifos and cypermethrin in/on unripe sapota fruit peel, pulp and whole unripe sapota fruits

\begin{tabular}{|c|c|c|c|c|c|c|c|c|c|c|c|c|}
\hline \multirow{4}{*}{$\begin{array}{l}\text { Days after } \\
\text { application }\end{array}$} & \multicolumn{12}{|c|}{ Residues recovered $\left(\mathrm{mg} \mathrm{kg}^{-1}\right)^{*}$} \\
\hline & \multicolumn{4}{|c|}{ Sapota Peel } & \multicolumn{4}{|c|}{ Sapota pulp } & \multicolumn{4}{|c|}{ Whole Unripefruit } \\
\hline & \multicolumn{2}{|c|}{ Chlorpyrifos } & \multicolumn{2}{|c|}{ Cypermethrin } & \multicolumn{2}{|c|}{ Chlorpyrifos } & \multicolumn{2}{|c|}{ Cypermethrin } & \multicolumn{2}{|c|}{ Chlorpyrifos } & \multicolumn{2}{|c|}{ Cypermethrin } \\
\hline & RD & 2XRD & RD & 2XRD & RD & 2XRD & RD & 2XRD & RD & 2XRD & RD & 2XRD \\
\hline 0 (1 h) & $\begin{array}{c}1.830 \\
(-)\end{array}$ & $\begin{array}{c}2.650 \\
(-)\end{array}$ & $\begin{array}{c}0.26 \\
(-)\end{array}$ & $\begin{array}{c}0.32 \\
(-)\end{array}$ & BDL & BDL & BDL & BDL & $\begin{array}{c}0.142 \\
(-)\end{array}$ & $\begin{array}{c}0.206 \\
(-)\end{array}$ & $\begin{array}{c}0.020 \\
(-)\end{array}$ & $\begin{array}{c}0.025 \\
(-)\end{array}$ \\
\hline 1 & $\begin{array}{c}1.360 \\
(25.68)^{* *}\end{array}$ & $\begin{array}{c}2.190 \\
(17.36)\end{array}$ & $\begin{array}{c}0.21 \\
(19.23)\end{array}$ & $\begin{array}{c}0.24 \\
(25.00)\end{array}$ & BDL & BDL & BDL & BDL & $\begin{array}{c}0.105 \\
(26.06)\end{array}$ & $\begin{array}{c}0.170 \\
(17.48)\end{array}$ & $\begin{array}{l}0.016 \\
(20.0)\end{array}$ & $\begin{array}{l}0.019 \\
(24.0)\end{array}$ \\
\hline 3 & $\begin{array}{c}0.840 \\
(54.10)\end{array}$ & $\begin{array}{c}1.750 \\
(33.96)\end{array}$ & $\begin{array}{c}0.15 \\
(42.23)\end{array}$ & $\begin{array}{c}0.21 \\
(34.38)\end{array}$ & BDL & BDL & BDL & BDL & $\begin{array}{c}0.065 \\
(54.23)\end{array}$ & $\begin{array}{c}0.136 \\
(33.98)\end{array}$ & $\begin{array}{l}0.012 \\
(40.0)\end{array}$ & $\begin{array}{l}0.016 \\
(36.0)\end{array}$ \\
\hline 5 & $\begin{array}{c}0.630 \\
(65.57)\end{array}$ & $\begin{array}{c}1.090 \\
(58.87)\end{array}$ & $\begin{array}{c}0.11 \\
(57.69)\end{array}$ & $\begin{array}{c}0.15 \\
(53.13)\end{array}$ & BDL & BDL & BDL & BDL & $\begin{array}{c}0.049 \\
(65.49)\end{array}$ & $\begin{array}{c}0.085 \\
(58.74)\end{array}$ & $\begin{array}{l}0.009 \\
(55.0)\end{array}$ & $\begin{array}{l}0.012 \\
(52.0)\end{array}$ \\
\hline 7 & $\begin{array}{c}0.270 \\
(85.25)\end{array}$ & $\begin{array}{c}0.830 \\
(68.68)\end{array}$ & $\begin{array}{c}0.08 \\
(69.23)\end{array}$ & $\begin{array}{c}0.09 \\
(61.88)\end{array}$ & BDL & BDL & BDL & BDL & $\begin{array}{c}0.021 \\
(85.21)\end{array}$ & $\begin{array}{c}0.065 \\
(68.45)\end{array}$ & $\begin{array}{l}0.006 \\
(70.0)\end{array}$ & $\begin{array}{l}0.007 \\
(72.0)\end{array}$ \\
\hline 10 & $\begin{array}{c}0.160 \\
(91.26)\end{array}$ & $\begin{array}{c}0.540 \\
(79.62)\end{array}$ & $\begin{array}{c}0.03 \\
(88.46)\end{array}$ & $\begin{array}{c}0.04 \\
(87.50) \\
\end{array}$ & BDL & BDL & BDL & BDL & $\begin{array}{c}0.012 \\
(91.55)\end{array}$ & $\begin{array}{c}0.042 \\
(79.61)\end{array}$ & BDL & BDL \\
\hline 20 & $\begin{array}{c}0.008 \\
(99.56)\end{array}$ & $\begin{array}{c}0.130 \\
(95.09)\end{array}$ & BDL & BDL & BDL & BDL & BDL & BDL & BDL & $\begin{array}{c}0.010 \\
(95.15)\end{array}$ & BDL & BDL \\
\hline 30 & BDL & $\begin{array}{c}0.010 \\
(99.62)\end{array}$ & BDL & BDL & BDL & BDL & BDL & BDL & BDL & BDL & BDL & BDL \\
\hline LOQ $\left(\mathrm{mg} \mathrm{kg}^{-1}\right)$ & \multicolumn{2}{|c|}{0.004} & \multicolumn{2}{|c|}{0.006} & \multicolumn{2}{|c|}{0.004} & \multicolumn{2}{|c|}{0.006} & \multicolumn{2}{|c|}{0.004} & \\
\hline
\end{tabular}

* Average of 3 replicates, BDL-Below detectable level (<LOQ); ** Per cent dissipation over residues obtained on 0 day $(2$ hrs after application) 
Table.3 Dissipation pattern of chlorpyrifos and cypermethrin in peel, pulp and whole sapota fruits

\begin{tabular}{|c|c|c|c|c|c|c|}
\hline Insecticides & Commodity & Dose & Dissipation equation & $\mathbf{R}^{2}$ & DT50 & Waiting Period \\
\hline \multirow[t]{5}{*}{ Chlorpyrifos } & \multirow[t]{2}{*}{ Unripe sapota peel } & $\mathrm{RD}$ & $y=-0.1172 x+3.2927$ & 0.99 & 2.57 & 13.60 \\
\hline & & 2XRD & $y=-0.0752 x+2.4501$ & 0.98 & 4.00 & 23.29 \\
\hline & Unripe sapota pulp & RD & - & - & - & - \\
\hline & \multirow[t]{2}{*}{ Whole unripe sapota fruit } & RD & $y=-0.1071 x+2.1468$ & 0.98 & 2.57 & 4.18 \\
\hline & & 2XRD & $y=-0.0655 x+1.2934$ & 0.99 & 4.6 & 9.08 \\
\hline \multirow{4}{*}{ Cypermethrin } & \multirow[t]{2}{*}{ Unripe sapota pulp } & RD & - & - & - & - \\
\hline & & 2XRD & - & - & - & - \\
\hline & \multirow[t]{2}{*}{ Whole unripe sapota fruit } & RD & $y=-0.0787 x+0.2995$ & 0.99 & 3.83 & 1.00 \\
\hline & & $2 \mathrm{XRD}$ & $y=-0.0601 x+0.3712$ & 0.95 & 5.01 & 1.00 \\
\hline
\end{tabular}

Table.4 Residues of chlorpyrifos and cypermethrin in peel, pulp and whole unripe and ripened sapotafruits and soil

\begin{tabular}{|c|c|c|c|c|c|}
\hline \multirow[t]{3}{*}{ Commodity } & \multirow[t]{3}{*}{ Particular } & \multicolumn{4}{|c|}{ Residues recovered $\left(\mathrm{mg} \mathrm{kg}^{-1}\right)$} \\
\hline & & \multicolumn{2}{|c|}{ Chlorpyrifos } & \multicolumn{2}{|c|}{ Cypermethrin } \\
\hline & & RD & 2XRD & RD & 2XRD \\
\hline \multirow{3}{*}{$\begin{array}{l}\text { Sapota fruit unripe } \\
\qquad(2 \mathrm{~h})\end{array}$} & Peel & 1.83 & 2.65 & 0.26 & 0.32 \\
\hline & Pulp & BDL & BDL & BDL & BDL \\
\hline & whole & 0.142 & 0.206 & 0.20 & 0.025 \\
\hline \multirow[t]{3}{*}{ Ripened Sapota fruit } & Peel & 0.01 & 0.03 & 0.005 & 0.006 \\
\hline & Pulp & 0.008 & 0.023 & BDL & 0.008 \\
\hline & whole & 0.008 & 0.024 & 0.004 & 0.008 \\
\hline \multirow[t]{2}{*}{ Soil } & $\begin{array}{c}\text { 0 DAA } \\
\text { (2hrs after application) }\end{array}$ & 0.34 & 0.53 & BDL & $\mathrm{BDL}$ \\
\hline & $30 \mathrm{DAA}$ & BDL & BDL & BDL & BDL \\
\hline
\end{tabular}


Table.5 Physicochemical properties of chlorpyrifos and cypermethrin

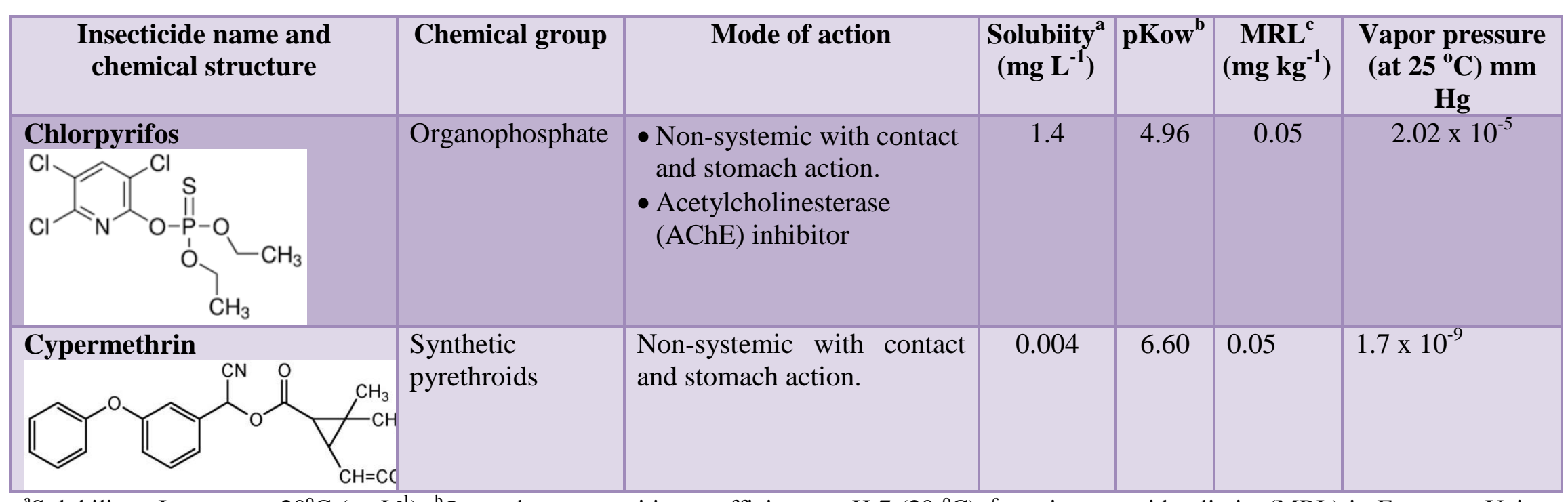

${ }^{\mathrm{a}}$ Solubility - In water at $20^{\circ} \mathrm{C}\left(\mathrm{mgL}^{-1}\right) ;{ }^{\mathrm{b}}$ Octanol-water partition coefficient at $\mathrm{pH} 7\left(20{ }^{\circ} \mathrm{C}\right) ;{ }^{\mathrm{c}}$ maximum residue limits (MRL) in European Union (2016)

Fig.1 Chromatographic separation of pesticide mixtures chlorpyrifos and cypermethrin $(0.1 \mathrm{ng} / \mu \mathrm{l})$ on GC-ECD

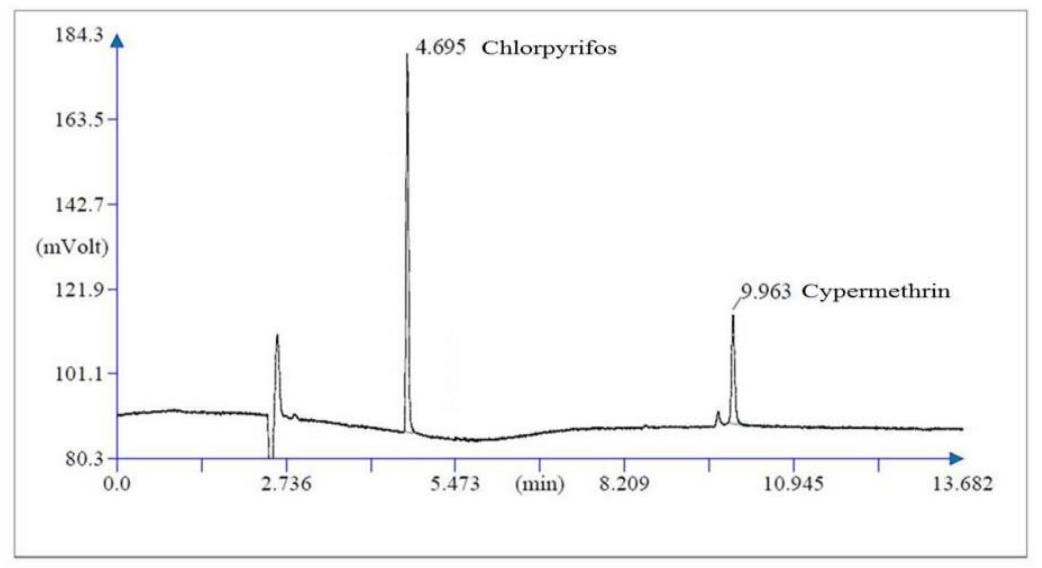


The latex of sapota might have prevented the migration of chlorpyrifos and cypermethrin residue to the inner part of the sapota (pulp). Similarly, Riccio et al., (2006) found that migration of chlorpyrifos methyl was arrested in peel having waxes in cuticle and epicuticle. Therefore, waxy substances act as hindrance to trans-peel migration of insecticides. Awasthi (1993) also reported that most of the pesticide residues are retained on peel of fruits and vegetables which is observed in our investigation. Contrary to unripen sapota fruits, slightly higher residues of chlorpyrifos and cypermethrin were observed in ripen sapota pulp than peel. Migration of insecticides from peel to pulp in ripen sapota fruit might be facilitated due to freshly harvested sapota fruits are subjected to rubbing with gunny bags which might reduce the thickness of peel and pulp-to-peel ratio increases during ripening of sapota (Pathak and Bhat, 1953). Furthermore, drastic reduction in gummy latex in ripe sapota fruits also hastened the trans-peel movement of insecticides residues in ripen sapota fruit. On whole fruit basis, the residues of chlorpyrifos and cypermethrin were lost due to ripening process in lieu of 88.35 to $94.37 \%$ and 68 to $98 \%$ respectively. This is also indicative of observance of safe waiting period of obtained in present study i.e. 4.18 days reduced the toxic residues of chlorpyrifos and cypermethrin below MRL $\left(0.05 \mathrm{mgkg}^{-1}\right)$. The residues of chlorpyrifos obtained in soil collected on 0 days indicates that chlorpyrifos is more persistent in soil and prone to drift loss due higher vapour pressure.

From the results obtained in the present study it can be infer that application of pre-mix formulation $\mathrm{NAAG}^{\circledR} 55 \mathrm{EC} \quad\left(1 \mathrm{mLL}^{-1}\right)$ resulted higher persistent 10-20 days for both insecticides i.e. chlorpyrifos and cypermethrin. The residues of cypermethrin dissipated faster as their residues were below detection level on 10day after application while that for chlorpyrifos was 20-30 days in unripe sapota fruits. The waiting period of 4-5 days is suggested to get chlorpyrifos and cypermethrin residue free whole sapota fruits. The residues of both insecticides were arrested on peel and no trans-peel movement of either of the insecticide was observed in unripen sapota fruits. Approximately, 60-95 $\%$ residues observed on unripen sapota fruit were lost due to ripening. Thus, consumption of ripen sapota fruit after removing the peel found safe as ripening process drastically reduced the amount of toxic residues of chlorpyrifos and cypermethrin.

\section{References}

Amvrazi, E.G. 2011. Fate of Pesticide Residues on Raw Agricultural Crops after Postharvest Storage and Food Processing to Edible Portions, Pesticides - Formulations, Effects, Fate, Prof. Margarita Stoytcheva (Ed.), InTech, DOI: 10.5772/13988. Available from: https://www.intechopen.com.

Anonymous, 2014. Indian Horticultural Data Base, National Horticultural Board, Gurgaon, India, pp 125.

AOAC Official Method. 2007, Pesticide Residues in Foods by Acetonitrile Extraction and Partitioning with Magnesium Sulfate. Method No. 2007.01. $19^{\text {th }} \quad$ Edition. http://www.weber.hu/PDFs/QuEChER S/AOAC_2007_01.pdf

Awasthi, M. D. 1993. Decontamination of insecticide residues on mango by washing and peeling. Journal of Food Science Technology. 30:132- 133.

Bostanian, N. J., Belanger, J. A., Boudreau, F. and Maillouxr, G. 1993. Dissipation of cyhalothrin residues on apple foliage and apples at harvest. Journal of Agricultural and Food Chemistry.41: 292-295. 
Butani, D. K., 1979. Insect and Fruits. Periodical Expert Book Agency, Delhi. pp. 87-94

Hoskins, W. M. 1961. Mathematical treatment of the rate of loss of pesticide residues. FAO plant protection B. 9: 163-168.

Jayanthi, PDK., Verghese, A. R., Honnamma, R., Nagaraju, D. K., 2006. Damage potential and seasonality of the sapodilla bud borer. International Journal of Tropical Insect Science. 26 (2): $86-91$.

Jhala, R. C., Shah, A. H., Patel, C. B., Patel, S. H., 1986. Population dynamics of some insect pests of sapota in South Gujarat. GAU Research Journal.11: 69-71.

Lambert, R. D., Dickey, E. E. and Thompson, N. S. 1968. Theuronic acids in hydrolyzate of Sapotegum. Carbohydrate Research.6:43-51.

Pathak,.S and Bhat, J. V. 1953. The carbohydrate metabolism of Acras sapota ruit. Journal University Bombay Section A. 21(5): 11-16.

Riccio, R., Trevisan, M. and Capri, E. 2006. Effect of surface waxes on the persistence of chlorpyrifos-methyl in apples, strawberries and grapefruits. Food Additives \& Contaminants. 23(7): 683-692.

SANCO.2013. Guidance document on analytical quality control and validation procedures for pesticide residues analysis in food and feed. $25: 1-42$

Somdutt, 2001. Fruit Crops: Sapota. In Hand Book of Horticulture, ICAR, New Delhi 110012, pp. 308-312.

Suryavanshi, S. S. and Patel, B. R. 2009. Evaluation of different insecticides against sapota bud borer, Anarsia achrasella Bradley. Karnataka Journal of Agricultural Sciences. 22(3): 722723.

Xu, X., Yu, S., Li R., Fan, J., Chen, S., Shen, H., Han, J., Huang, B. and Ren, Y. 2012. Distribution and migration study of pesticides between peel and pulp in grape by online gel permeation chromatography-gas chromatography/ mass spectrometry. Food Chemistry. 135: 161-169.

\section{How to cite this article:}

Vanrajsinh H. Solanki, Susheel Singh, Kelvin D. Gandhi, Kamlesh G. Patel and Keyur N. Patel. 2019. Persistence Behaviour of Pre-Mix Formulation of Profenophos and Cypermethrinin/on Sapota Fruit. Int.J.Curr.Microbiol.App.Sci. 8(01): 1250-1260. doi: https://doi.org/10.20546/ijcmas.2019.801.132 